\title{
Application of transforaminal-lumbar interbody fusion technology combined with lesion clearance and chemotherapy via catheter for the treatment of spinal tuberculosis
}

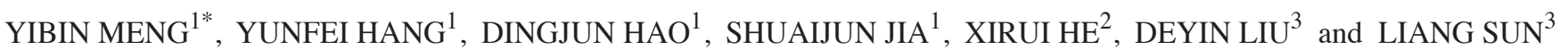 \\ Departments of ${ }^{1}$ Spine Surgery, ${ }^{2}$ Clinical Pharmacy and ${ }^{3}$ Orthopaedics, \\ Hong Hui Hospital Affiliated to Xi'an Jiaotong University, Xi'an, Shaanxi 710054, P.R. China
}

Received May 23, 2018; Accepted October 3, 2018

DOI: $10.3892 /$ etm.2019.7536

\begin{abstract}
The aim of the present study was to analyze the clinical and radiological outcomes of active thoracolumbar spinal tuberculosis (TB) treated by application of transforaminal-lumbar interbody fusion technology combined with lesion clearance and chemotherapy via catheter (TCLC). Posterior debridement and indwelling catheterization in the lesion area were performed for direct injection of anti-TB drugs, so as to reduce the recurrence rate. The present prospective study comprised 26 patients with active thoracolumbar spinal TB who underwent TCLC at Hong Hui Hospital affiliated to Xi'an Jiaotong University (Xi'an, China). The kyphotic Cobb angle at presentation, after surgery and at the final follow-up were $22.7 \pm 9.8,9.8 \pm 7.3$ and $10.3 \pm 8.8^{\circ}$, respectively, with an average correction of $13.1 \pm 5.4^{\circ}$ after surgery, and a loss of correction of $1.8 \pm 1.0^{\circ}$ at the final follow-up. The rate of correction and loss of correction were 56.6 and $8.3 \%$, respectively. At six months after the surgery, all abnormal erythrocyte sedimentation rates and C-reactive protein levels had returned to normal. The average time to union was $\sim 5$ months. All patients had bony union and improved neurological function, with their daily activity returning to normal. In conclusion, in the present study, application of TCLC for the treatment of spinal TB achieved satisfactory healing of lesions. The surgical treatment for spinal TB comprised the removal of
\end{abstract}

Correspondence to: Mr. Deyin Liu, Department of Orthopaedics, Hong Hui Hospital Affiliated to Xi'an Jiaotong University, 76 Nanguo Road, Xi'an, Shaanxi 710054, P.R. China

E-mail: deyinliu1@aliyun.com

"Contributed equally

Abbreviations: TB, tuberculosis; ESR, erythrocyte sedimentation rate; CRP, C-reactive protein; TLIF, transforaminal-lumbar interbody fusion; CT, computed tomography; INH, isonicotinic acid hydrazide; $\mathrm{PCD}$, percutaneous catheter drainage

Key words: spinal tuberculosis, transforaminal-lumbar interbody fusion, chemotherapy catheter the disease as far as possible, and the local administration of anti-TB chemotherapy to the lesion is key to successful treatment.

\section{Introduction}

Tuberculosis (TB) is a relatively common disease in developing countries, including China and India $(1,2)$. TB spondylitis is considered to be a serious type of TB disease. The incidence of spinal TB is increasing, with the spine being affected in an estimated $50 \%$ of cases with musculoskeletal involvement $(3,4)$. Previous studies have reported that surgical treatment is an important strategy for the treatment of spinal TB.

Regarding the surgical removal of spinal TB, bone grafting fusion is an important step in surgical therapy, which may improve spinal stability, allow for recovery of the spinal cord function and reduce the time to recovery for patients (5). The safety and efficacy of internal fixation for the treatment of spinal TB have been recognized by the majority of clinicians, and this treatment has an important role in stabilizing the decreased kyphotic deformity, reducing spinal cord compression.Hibbs (6) and Albee (7) reported on the posterior interbody fusion for spinal TB, also known as Pott's disease, as early as 1911. Anterior radical debridement and non-instrumented fusion have been described by Ito et al (8) in 1934, followed by Hodgson and Stock (9) in 1956. Combined anterior and posterior fusion has been described by Mukhtar et al (10) in 2003. In 2013, Kumar et al (11) reported on posterior interbody fusion for selected cases of thoracolumbar spinal TB without anterior instrumentation and without anterior or posterior bone grafting.

The aim of the present study was to analyze the clinical and radiological outcomes of active thoracolumbar spinal TB treated by application of transforaminal-lumbar interbody fusion (TLIF) technology combined with lesion clearance and chemotherapy via catheter (TCLC). The study was performed on 26 patients with active thoracolumbar spinal TB who underwent TCLC. The present study assessed the changes of the Cobb angle, erythrocyte sedimentation rate (ESR) and C-reactive protein (CRP) levels, the functional and radiological outcomes, and the fusion status of patients with spinal TB treated by using TCLC. 


\section{Patients and methods}

Patients. The present prospective study included 26 patients diagnosed with TB spondylitis involving the thoracic spine and lumbar spine. Permission from the Ethics Committee of Hong Hui Hospital (Xi'an, China) and written informed consent was obtained from the patients prior to the study commencing. The Patients underwent a TLIF procedure (unilateral decompression laminectomy, drainage of abscess and posterior pedicle screw implementation). Various patients with active TB spondylitis and with neurological involvement were included in the study, and the procedures were performed between October 2010 and October 2013. The pre-operative kyphosis angle ranged from 5 to $50^{\circ}$. Patients with severe and highly severe kyphosis $\left(>50^{\circ}\right)$, those with late-onset paraplegia of healed disease with thoracic spine a bony internal gibbus, and those with multi-segmental disease with destruction of $>2$ vertebral bodies were excluded.

The cohort comprised 17 men and 9 women, and their mean age was 45 years (range, 19-69 years). Neurological assessment was performed using Frankel grading (12); three patients were rated as Frankel grade B, six were of grade $\mathrm{C}$ and seven were of grade D. A total of 10 patients without any neurological deficits were assigned a Frankel grade E. For each of the patients, pre-operative anteroposterior and standing radiographs of the spine were recorded, and computed tomography (CT) scans, magnetic resonance imaging and hematological investigations, including complete blood cell count, ESR and CRP, were performed.

Surgical procedure. Under general anesthesia, patients were positioned in the prone position on the spinal table. The position of the affected vertebrae was confirmed using fluoroscopy. The involved segment was exposed via a midline posterior approach. Screws were temporarily connected by a rod on one side to avoid instability during decompression. Hemi-zygapophysial joints or bilateral zygapophysial joints were made at the involved segment while retaining the lamina as much as possible. Granulation tissue was debrided and the abscess, if present, was drained through the inter-transverse space. Pedicle screws were connected by rods and compression was applied to correct the kyphosis through a zygapophysial joint bone graft or lamina bone graft. An intra-operative biopsy was obtained and sent for histopathological examination. To maintain the stability of the spine and to facilitate post-operative vertebral fusion, an intervertebral bone graft from the ilium was placed. Prior to this, a $0.7-\mathrm{mm}$ epidural catheter was implanted in the lesion. The kyphosis was corrected as much as possible by applying compression between the screws prior to tightening them to the rods.

Post-operative treatment and rehabilitation. After the operation, patients were treated with $0.1 \mathrm{~g}$ isonicotinic acid hydrazide (INH) daily via injection through the catheter. The mean duration of follow-up for the retention of catheter was 2.2 months (range 2-4 months); four-drug chemotherapy $(25 \mathrm{mg} / \mathrm{ml}$ isoniazid, $15 \mathrm{mg} / \mathrm{ml}$ rifamycin sodium, $25 \mathrm{mg} / \mathrm{ml}$ streptomycin, $20 \mathrm{mg} / \mathrm{ml}$ acetazolamide; each administered orally) was continued for 3 months following catheter removal, followed by a two-drug regimen (INH and rifampicin) for a further period of 8 months.
Mobilization was started in ambulatory patients on the second post-operative day, and physiotherapy and sickbed mobilization was started in non-ambulatory patients. Post-operative bracing was continued for a minimum period of 3 months following surgery in all patients. The disease was considered healed when clinical evaluation indicated no spinal tenderness or spasm, hematological parameters returned to near normal levels and spinal fusion was evident on follow-up radiographs. Radiographically, fusion was considered to be complete when a bony bridge with trabeculation equal in density to the adjacent vertebrae was present, radiolucent zones were absent and no abnormal mobility $\left(<5^{\circ}\right.$ of movement) was observed at the fused segment on post-operative flexion-extension radiographs. These criteria were previously described by Schofferman et al (13) and Kim et al (14).

Statistical analysis. All calculations were performed using SPSS 17.0 (SPSS, Inc., Chicago, IL, USA). Results were presented as mean \pm standard deviation. Comparisons between the three groups were performed using an unpaired t-test and one-way analysis of variance followed by a Levene test. $\mathrm{P}<0.05$ was considered to indicate a statistically significant result.

\section{Results}

Pre-operative patient characteristics. The present study comprised 26 patients diagnosed with TB spondylitis involving the thoracic spine and lumbar spine. Patients with active TB spondylitis and with neurological involvement were included in the study. The pre-operative kyphosis angle ranged from 5 to $50^{\circ}$. The cohort comprised 17 men and 9 women, and their mean age was 45 years (range, 19-69 years). The mean duration of follow-up was 14.1 months (range, 9-24 months). The locations of the lesions were distributed as follows: A total of 3 cases of lumbar 2-3, 8 cases of lumbar 3-4, 12 cases of lumbar 4-5 and 7 cases of lumbar 5-sacral 1 involvement. Of the 19 cases with paravertebral abscesses, 9 had psoas abscesses. The demographic and clinical characteristics of the patients are presented in Table I.

Surgery and outcomes. In the present study, the mean duration of the operation was $130 \mathrm{~min}$ (range, 112-170 min), the mean intra-operative blood loss was $550 \mathrm{ml}$ (range, $470-820 \mathrm{ml}$ ) and the mean duration of hospital stay was 7 days (range, 5-10 days). Data on the pre- and post-operative ESR and CRP are presented in Table II. The number of patients with normal ESR before operation was 4, CRP was 6, while the number of patients with normal ESR after operation was 6, CRP was 10 in the first month. All patients with neurological deficits exhibited an improvement in Frankel grading post-operatively (Table III). The mean pre-operative kyphosis angle was $32.4^{\circ}$ (range, $5-50^{\circ}$ ). The angle of kyphosis was reduced to a mean of $7.2^{\circ}$ in the immediate post-operative period (range, $0-12^{\circ}$ ), and the difference was statistically significant $(\mathrm{P}<0.005)$.

Follow-up results. At the time of the final follow-up, the mean kyphotic Cobb angle at presentation, after surgery and at the final follow-up were $22.7 \pm 9.8,9.8 \pm 7.3$ and $10.3 \pm 8.8^{\circ}$, respectively, with an average correction of $13.1 \pm 5.4^{\circ}$ after surgery, and a loss of correction of $1.8 \pm 1.0^{\circ}$ at the final follow-up (Table IV). 
Table I. Demographic and clinical characteristics of patients $(n=26)$.

\begin{tabular}{lc}
\hline Variables & Value \\
\hline Mean age (range, 19-69 years) & $45.4 \pm 10.5$ \\
Gender & 17 \\
Male & \\
Female & 9 \\
Occupation & \\
Farmer & 21 \\
Other-c & 5 \\
Educational level & 18 \\
Basic school education & 8 \\
Higher school education & $14.1 \pm 3.9$ \\
Duration of TB (months) & \\
Other body sites infected & 24 \\
Thoracolumbar spine & 2 \\
Otherd,e & \\
\hline
\end{tabular}

Values are expressed as $\mathrm{n}$ or the mean \pm standard deviation. TB, tuberculosis; CI, confidence interval. ${ }^{a}$ docotor, ${ }^{b}$ worker, ${ }^{c}$ educator, ${ }^{\mathrm{d} l u n g}$ and ${ }^{\mathrm{e}}$ chest.

Table II. Amount of patients with normal ESR and CRP levels prior to surgery and at various post-OP stages.

\begin{tabular}{lrr}
\hline Time-point & \multicolumn{1}{c}{ ESR } & \multicolumn{1}{c}{ CRP } \\
\hline Pre-OP Post-OP (months) & $4(15.3)$ & $6(23.1)$ \\
1 & $6(23.1)$ & $10(38.5)$ \\
3 & $15(57.7)$ & $16(61.5)$ \\
6 & $26(100)$ & $26(100)$ \\
\hline
\end{tabular}

Values are expressed as n (\%). ESR, erythrocyte sedimentation rate; $\mathrm{CRP}, \mathrm{C}$-reactive protein; OP, operation.

The rate of correction and loss of correction were 56.6 and $8.3 \%$, respectively. Complications were minor in nature and included delayed wound healing in 1 patient and sinus formation in 1 patient. No major complications were reported. The anterior vertebral lesions healed through bony fusion, which was completed between 6 and 7 months post-operatively (Figs. 1 and 2).

\section{Discussion}

In recent years, multiple treatments have been proposed for spinal TB, but most clinicians perform isolated anterior lesion clearance or posterior fixation fusion. Certain studies have described the application of isolated anterior instrumented fusion with good results $(15,16)$. According to certain studies, single anterior debridement and bone grafting are frequently unsatisfactory in correcting kyphosis deformity or preventing its progression (17-19). However, others have reported good
Table III. Post-operative Frankel grading (n).

\begin{tabular}{lllllr}
\hline & \multicolumn{5}{c}{ Frankel grade (post-operative) } \\
\cline { 2 - 6 } Pre-operative & A & B & C & D & E \\
\hline A & 0 & 0 & 0 & 0 & 0 \\
B & 0 & 0 & 0 & 2 & 1 \\
C & 0 & 0 & 0 & 2 & 4 \\
D & 0 & 0 & 0 & 2 & 5 \\
E & 0 & 0 & 0 & 0 & 10 \\
\hline
\end{tabular}

Table IV. Kyphotic Cobb angle at presentation following surgery.

\begin{tabular}{lcccc}
\hline Time & 1 & 2 & 3 & Mean \\
\hline $\begin{array}{l}\text { Kyphotic } \\
\text { Cobb angle }\end{array}$ & $22.7 \pm 9.8^{\circ}$ & $9.8 \pm 7.3^{\circ}$ & $10.3 \pm 8.8^{\circ}$ & $13.1 \pm 5.4^{\circ}$ \\
\hline
\end{tabular}

outcomes for posterior fusion. Studies including that by Güven et al (20) used CT- or ultrasound-guided percutaneous catheter drainage (PCD) to treat TB with abscess formation (21-23). Based on the results of long-term observation, PCD is a safe, effective, minimally invasive treatment method with advantages for abscess treatment, but it does not resolve complications including deformity, severe nerve dysfunction or spinal instability. However, local chemotherapy for TB infection is effective, as it acts directly on the lesions. This is particularly useful for TB patients after surgery, as they are likely to present with post-operative scarring around lesions and a limited local blood supply due to destruction of blood vessels during surgery, which may lead to reduced concentrations of systemic drugs and reduce the effectiveness of systemic TB drugs. Furthermore, the anterior approach may damage the spinal segment and the diaphragm. Soares Do Brito et al (24) have reported a higher incidence of complications arising from single anterior fusion compared with those associated with individual post-fusion (25-29). McDonnell et al (30) have reported higher complication rates for single-event anterior and posterior fusions compared with multi-stage anterior and posterior fusions. They obtained an incidence of major complications of $11 \%$ and an incidence of minor complications of $24 \%$. Simultaneous multi-level spinal TB surgery has become popular due to its satisfactory clinical outcomes $(31,32)$; the disadvantages of combined anterior and posterior approaches include bleeding, long operation time and complications associated with the anterior approach $(33,34)$.

For the treatment of spinal TB, posterior debridement, intervertebral bone graft fusion and internal fixation compared with anterior and posterior surgery has the following advantages: i) The anatomic approach is a simple operation with little trauma, while anterior surgery requires a wide exposure, and a combined anterior and posterior approach further increases the surgical trauma. ii) Posterior surgery avoids thoracotomy and abdominal surgery, and reduces trauma to the lungs and 


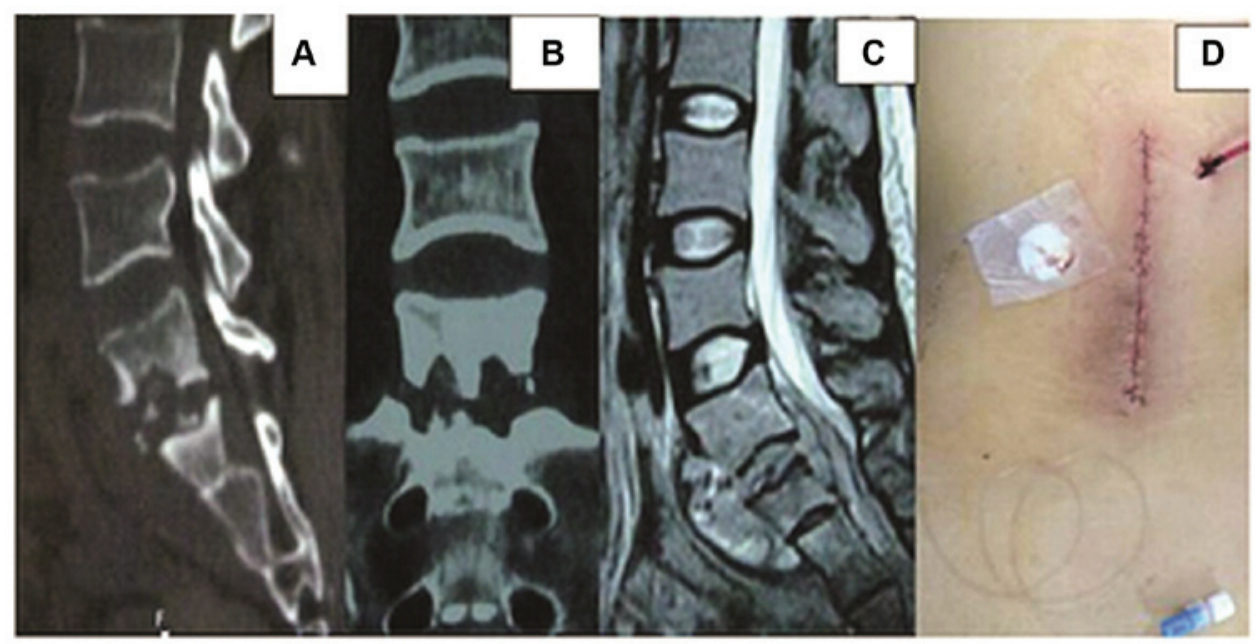

Figure 1. Representative case of a 32-year-old male patient. (A and B) Sagittal 3-dimensional computed tomography images indicating the destruction of the L5 and S1 vertebrae. (C) Sagittal T2-weighted magnetic resonance image displaying the destruction of the L5 and S1 vertebrae, with an abscess on the vertebral side. (D) Externally, the incision and an indwelling epidural catheter are visible after the surgery.

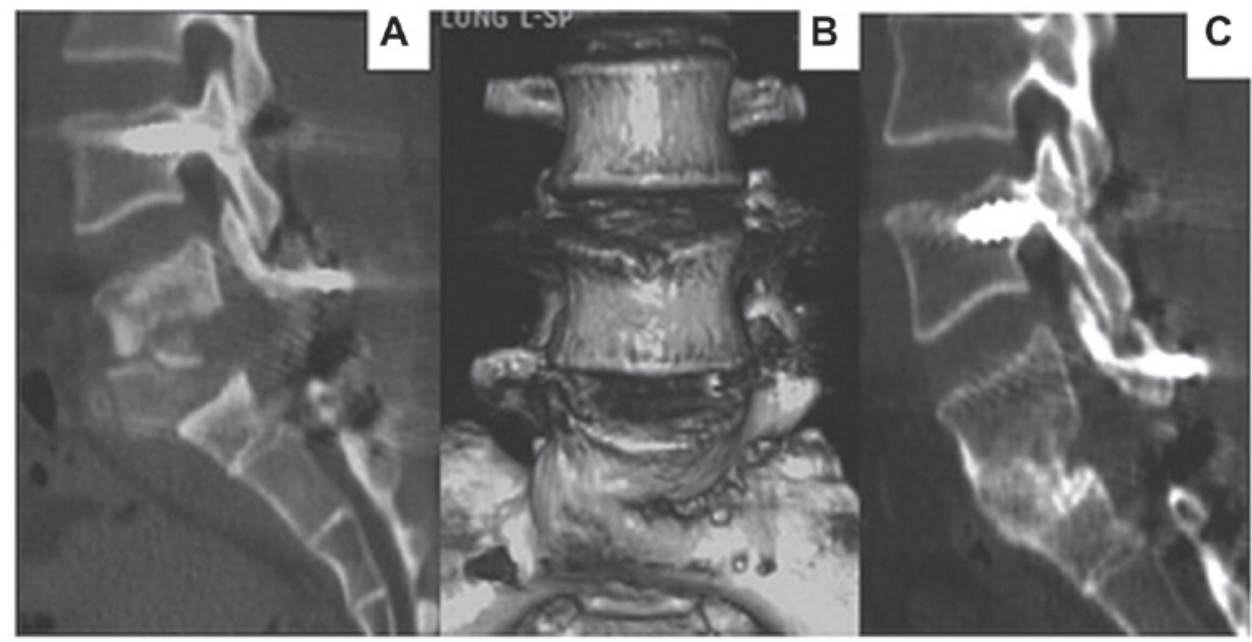

Figure 2. Representative case of the same 32-year-old male patient. (A) Sagittal 3D computed tomography image displaying the removal of tuberculosis and bone graft. (B and C) Sagittal 3D computed tomography image demonstrating the fusion of the intervertebral bone graft between 6 and 7 months post-operation. 3D, 3-dimensional.

abdominal cavity viscera, with a consequently low incidence of complications. iii) Posterior osteotomy using a pedicle screw rod system fixation of the spinal column provides superior deformity correction with a sustained effect, allowing the vertebral lamina bone graft to reach $360^{\circ}$. iv) Combined with fixation of the diseased vertebrae, this approach reduces the internal fixation and fusion range, avoiding excessive loss of spinal movement units and associated complications.

Certain experts have raised concerns regarding posterior surgery alone for $\mathrm{TB}$, mainly for the following reasons: i) Posterior surgery may destroy the originally normal posterior column structure, potentially aggravating spinal instability (35-37) and ii) The presence of anterior foci indicates the risk of spreading to the rear of the spine (38). In the present study, these disadvantages were avoided by selecting an appropriate operation scheme: i) Since the posterior approach cannot completely clear the lesion in all cases and dissemination is possible, a catheter was inserted during surgery for local chemotherapy, through which anti-TB drugs were directly administered; thereby, sufficient drug supply to the site of the lesion was guaranteed and ii) TLIF technology was used to gain access from a unilateral intervertebral foramen, avoiding bilateral decompression as far as possible and reducing the destruction of the posterior column.

The present study indicated that the TLIF approach is sufficient in adults with spinal TB for the following reasons: i) Effective chemotherapy via catheter is provided to sterilize the vertebral body lesions without the requirement for excessive anterior debridement or fusion; ii) Complications associated with anterior approaches to the thoracolumbar spine may be avoided; iii) TLIF technology may stabilize the vertebral column and is conducive to vertebral fusion and stability and iv) Inter-body bone grafting promotes interbody fusion, permitting patients to undertake early rehabilitation.

However, the present study had certain deficiencies. The amount of data obtained to support that TCLC was insufficient. 
In addition, the follow-up duration was relatively short. A future prospective study with long-term follow-up of patients treated with a posterior approach, including abscess clearance, bone fusion and internal fixation for the treatment of complex thoracic and lumbar spinal TB is required to provide further evidence-based outcomes.

In conclusion, the present study indicated that application of TCLC for the treatment of spinal TB provides satisfactory healing of the lesions. During surgery, TB lesions were removed as far as possible. After the operation, local chemotherapy with INH via catheter was essential for the successful treatment of TB.

\section{Acknowledgements}

Not applicable.

\section{Funding}

The present study was supported by the Natural Science Foundation of Shaanxi Province, China (grant no. 2017JM8054).

\section{Availability of data and materials}

The data and materials used in the present study are available upon reasonable request from the corresponding author.

\section{Authors' contributions}

DL and LS participated in the study design, data analysis and manuscript drafting. YM and YH were mainly responsible for the patient treatment, data interpretation and revision of the manuscript. DH collected the information of the participants of this study. SJ and $\mathrm{XH}$ were involved in part of the patient treatment and data analysis.

\section{Ethics approval and consent to participate}

Ethics approval was obtained from the Ethics Committee of Hong Hui Hospital (Xi'an, China) and all participants provided written informed consent prior to the study.

\section{Patient consent for publication}

All the patients were informed and agreed with the publication.

\section{Competing interests}

The authors declare that they have no competing interests.

\section{Reference}

1. China Tuberculosis Control Collaboration: The effect of tuberculosis control in China. Lancet 364: 417-422, 2004.

2. Padmapriyadarsini C, Shobana M, Lakshmi M, Beena T and Swaminathan S: Undernutrition \& tuberculosis in India: Situation analysis \& the way forward. Indian J Med Res 144: 11-20, 2016.

3. Zhang HQ, Tang MX and Wang YX: Using multiple special formed titanium mesh cages to treat spinal tuberculosis via posterior approach only. Orthop J Chin 22: 1353-1358, 2014 (In Chinese)
4. Rivas-Garcia A, Sarria-Estrada S, Torrents-Odin C, Casas-Gomila L and Franquet E: Imaging findings of Pott's disease. Eur Spine J 22 (Suppl 4): S567-S578, 2013.

5. Moon MS: Development in the management of tuberculosis of the spine. Curr Orthop 20: 132-140, 2006.

6. Hibbs RA: An operation for Pott's disease of the spine. J Am Med Assoc 59: 433-436, 1912.

7. Albee FH: Transplantation of a portion of the tibia into the spine for Pott's disease: A preliminary report 1911. Clin Orthop Relat Res 460: 14-16, 2007.

8. Ito $\mathrm{H}$, Tsuchiya $\mathbf{J}$ and Asami G: A new radical operation for Pott's disease. Report of ten cases. J Bone Joint Surg 16: 499-515, 1934.

9. Hodgson AR and Stock FE: Anterior spinal fusion a preliminary communication on the radical treatment of Pott's disease and Pott's paraplegia. Br J Surg 44: 266-275, 1956.

10. Mukhtar AM, Farghaly MM and Ahmed SH: Surgical treatment of thoracic and lumbar tuberculosis by anterior interbody fusion and posterior instrumentation. Med Princ Pract 12: 92-96, 2003.

11. Kumar MN, Joseph B and Manur R: Isolated posterior instrumentation for selected cases of thoracol-umbar spinal tuberculosis without anterior instrumentation and without anterior or posterior bone grafting. Eur Spine J 22: 624-632, 2013.

12. Li S1, Li Z, Hua W, Wang K, Li S, Zhang Y, Ye Z, Shao Z, Wu X and Yang C: Clinical outcome and surgical strategies for late post-traumatic kyphosis after failed thoracolumbar fracture operation: Case report and literature review. Medicine (Baltimore) 96: e8770, 2017.

13. Schofferman J, Slosar P, Reynolds J, Goldthwaite N and Koestler M: A prospective randomized comparison of 270 degree fusions to 360 degree fusions (circumferential fusions). Spine (Phila Pa 1976) 26: E207-E212, 2001.

14. Kim KT, Lee SH, Lee YH, Bae SC and Suk KS: Clinical outcomes of 3 fusion methods through the posterior approach in the lumbar spine. Spine (Phila Pa 1976) 31: 1351-1357, 2006.

15. Benli IT, Acaroğlu E, Akalin S, Kis M, Duman E and Un A: Anterior radical debridement and anterior instrumentation in tuberculosis spondylitis. Eur Spine J 12: 224-234, 2003.

16. Jin D, Qu D, Chen J and Zhang H: One-stage anterior interbody autografting and instrumentation in primary surgical management of thoracolumbar spinal tuberculosis. Eur Spine J 13: 114-121, 2004.

17. Pang X, Shen X, Wu P, Luo C, Xu Z and Wang X: Thoracolumbar spinal tuberculosis with psoas abscesses treated by one-stage posterior transforaminal lumbar debridement, interbody fusion, posterior instrumentation, and postural drainage. Arch Orthop Trauma Surg 133: 765-772, 2013.

18. Zhang HQ, Lin MZ, Shen KY, Ge L, Li JS, Tang MX, Wu JH and Liu JY: Surgical management for multilevel noncontiguous thoracic spinal tuberculosis by single-stage posterior transforaminal thoracic debridement, limited decompression, interbody fusion, and posterior instrumentation (modified TTIF). Arch Orthop Trauma Surg 132: 751-757, 2012.

19. Singh K, Vaccaro AR, Kim J, Lorenz EP, Lim TH and An HS: Biomechanical comparison of cervical spine reconstructive techniques after a multilevel corpectomy of the cervical spine. Spine (Phila Pa 1976) 28: 2352-2358, 2003.

20. Güven O, Kumano K, Yalçin S, Karahan M and Tsuji S: A single stage posterior approach and rigid fixation for preventing kyphosis in the treatment of spinal tuberculosis. Spine (Phila Pa 1976) 19: 1039-1043, 1994.

21. Pombo F, Martín-Egaña R, Cela A, Díaz JL, Linares-Mondéjar P and Freire M: Percutaneous catheter drainage of tuberculous psoas abscesses. Acta Radiol 34: 366-368, 1993.

22. Gupta S, Suri S, Gulati M and Singh P: Ilio-psoas abscesses: Percutaneous drainage under image guidance. Clin Radiol 52: 704-707, 1997.

23. Dinç H, Ahmetoğlu A, Baykal S, Sari A, Sayil O and Gümele HR: Image-guided percutaneous drainage of tuberculous iliopsoas and spondylodiskitic abscesses: Midterm results. Radiology 225: 353-358, 2002.

24. Soares Do Brito J, Tirado A and Fernandes P: Surgical treatment of spinal tuberculosis complicated with extensive abscess. Iowa Orthop J 34: 129-136, 2014.

25. Soares do Brito J, Batista N, Tirado A and Fernandes P: Surgical treatment of spinal tuberculosis: An orthopedic service experience. Acta Med Port 26: 349-356, 2013 (In Portuguese).

26. Shi JD, Wang Q and Wang ZL: Primary issues in the selection of surgical procedures for thoracic and lumbar spinal tuberculosis. Orthop Surg 6: 259-268, 2014. 
27. Garg B, Kandwal P, Nagaraja UB, Goswami A and Jayaswal A: Anterior versus posterior procedure for surgical treatment of thoracolumbar tuberculosis: A retrospective analysis. Indian J Orthop 46: 165-170, 2012.

28. Pola E, Rossi B, Nasto LA, Colangelo D and Logroscino CA Surgical treatment of tuberculous spondylodiscitis. Eur Rev Med Pharmacol Sci 16 (Suppl 2): S79-S85, 2012.

29. Ma YZ, Cui X, Li HW, Chen X, Cai XJ and Bai YB: Outcomes of anterior and posterior instrumentation under different surgical procedures for treating thoracic and lumbar spinal tuberculosis in adults. Int Orthop 36: 299-305, 2012.

30. McDonnell MF, Glassman SD, Dimar JR II, Puno RM and Johnson JR: Perioperative complications of anterior procedures on the spine. J Bone Joint Surg Am 78: 839-847, 1996.

31. Qureshi MA, Khalique AB, Afzal W, Pasha IF and Aebi M: Surgical management of contiguous multilevel thoracolumbar tuberculous spondylitis. Eur Spine J 22 (Suppl 4): S618-S623, 2013.

32. Zhang HQ, Guo CF, Xiao XG, Long WR, Deng ZS and Chen J: One-stage surgical management for multilevel tuberculous spondylitis of the upper thoracic region by anterior decompression, strut autografting, posterior instrumentation, and fusion. J Spinal Disord Tech 20: 263-267, 2007.
33. Zeng H, Shen X, Luo C, Xu Z, Zhang Y, Liu Z and Wang X: Comparison of three surgical approaches for cervicothoracic spinal tuberculosis: A retrospective case-control study. J Orthop Surg Res 10: 100, 2015.

34. Zeng H, Wang X, Pang X, Luo C, Zhang P, Peng W, Wu P and $\mathrm{Xu} \mathrm{Z}$ : Posterior only versus combined posterior and anterior approaches in surgical management of lumbosacral tuberculosis with paraspinal abscess in adults. Eur J Trauma Emerg Surg 40: 607-616, 2014.

35. Güzey FK, Emel E, Bas NS, Hacisalihoglu S, Seyithanoglu MH, Karacor SE, Ozkan N, Alatas I and Sel B: Thoracic and lumbar tuberculous spondylitis treated by posterior debridement, graft placement, and instrumentation: A retrospective analysis in 19 cases. J Neurosurg Spine 3: 450-458, 2005.

36. Jain AK: Tuberculosis of the spine: A fresh look at an old disease. J Bone Joint Surg Br 92: 905-913, 2010.

37. Tuli SM: Tuberculosis of the spine: A historical review. Clin Orthop Relat Res 460: 29-38, 2007.

38. Int Veld BA, Rettig TCD, de Heij N, de Vries J, Wolfs JFC and Arts MP: Maintaining endotracheal tube cuff pressure at $20 \mathrm{mmHg}$ during anterior cervical spine surgery to prevent dysphagia: A double-blind randomized controlled trial. Eur Spine J, Oct 25, 2018 (Epub ahead of print). 